these were described the effects of oxygen, carbon dioxide and hydrocyanic acid in various gas mixtures on the zymasic breakdown of hexose. In addition to anaerobic zymasis, he has demonstrated that other types exist produced by the gases just named, and by injury and senescence. Having come to definite conclusions as to the conditions of the various forms of zymasis, he has examined the relations between the phenomenon and the incidence of physiological diseases. Naturally, during the War, the whole of these researches were suspended, or at least slowed down, by Prof. Thomas's activities in the O.T.C., in which he held the rank of captain. However, during the past year, they have been recommenced along some of the more promising lines, so that there is every probability that his tenure of the professorship will be marked by a steady flow of research papers continuing the investigations which have been so productive of results in the past.

\section{Patterson Medal in Meteorology}

THe inauguration has been announced of a Patterson Medal to be awarded annually to a resident of Canada or Newfoundland for achievement in meteorology. The Medal has been founded by the friends and professional ass ciates of Dr. John Patterson, the retiring controller of the Meteorological Service of Canada and hongrary professor of meteorology in the University of Poronto. After graduating from the University of Tofonto in 1900 , Dr. Patterson went to the Cavendisb/Laboratory, Cambridge, with an 1851 Exhibition Scence Research Scholarship. In 1902 he became professor of physics at the University of Allahabad, and soon afterwards he was appointed Imperial meteorologist to the Government of India. He joined the Meteorological Service of Canada in 1910 and became director in 1929. During the First World War, Dr. Patterson worked with the British Admiralty to develop a commercial process for the extraction of helium from natural gas. After the War, to meet the demands of aviation, he trained young graduates for the Canadian Meteorological Service, and when the Second World War broke out, he had already laid the foundation of a great meteorological service which was able to meet the demands of the British Commonwealth Air Training Plan. He is best known for his pioneering work in the exploration of the upper atmosphere by means of balloon meteorographs and for improvements to the cup anemometer and mercury barometer.

The announcement of the Patterson Medal was made by the Hon. C. D. Howe, Minister of Reconstruction and Supply in Canada, at a reception and dinner given to Dr. Patterson on September 28. Commander C. P. Edwards, Deputy Minister of Transport, presented him with a portrait which Dr. Patterson requested should be hung at the headquarters of the Meteorological Office along with the portraits of the six preceding directors. Commander Edwards then presented a silver platter with an inscription expressing the esteem in which Dr. Patterson is held by colleagues and other friends. In reply, Dr. Patterson said he was deeply gratified that his friends had chosen to honour him by the foundation of the Medal, since it would foster the advancement of meteorological science. Nations have founded great institutions for the development of other sciences, and scholarships and awards have been set up, yet this science, which bears upon the life of every human being, had not received the attention it merited. This was the first time in Canada that there had been any award for meteorology. The building of a good meteorological service depends, he said, on two essentials : the obtaining of basic data and the provision of technical staff capable of making the most of the data. Surface meteorological observations are only obtainable regularly from one fifth of the surface of the globe. The augmentation of basic data is taking place to-day from the upper air. This data has become very expensive, by prewar standards. The provision of a technical staff competent to make the most of this data would only add a few per cent to the total cost of the service; failure to provide this staff would be false economy.

\section{Principles of Rheological Measurement}

A CONFERENCE and exhibition of rheological research apparatus were arranged by the British Rheologists' Club during October 3-5 at Bedford College, Uniy ersity of London. Prof. E. N. da C. Andrade, in a presidential address, gave a survey of modern theory with special reference to metals and hard paterials in general. Three sessions were devoted to the principles of rheological measurement for $(a)$ soft materials under conditions of large strain, (b) materials of intermediate consistency, such as doughs, pastes, rubber, etc., and $(c)$ steel and hard materials. Dr. L. R. G. Treloar spoke on "Technical Terms and Definitions". Mr. E. G. Ellis, chairman of the Grease Rheology Panel of the Institute of Petrol. eum, spoke on the measurement of the consistency of lubricating greases. Dr. K. Weissenberg with Mr. G. M. Freeman, of the British Cotton Industry Research Association, dealt with the geometry of rheological phenomena and demonstrated the practical application of the Weissenberg rheogoniometer. Dr. G. W. Scott Blair read a paper on the consistency of doughs and pastes, and Mr. J. M. Buist on the hardness testing of rubbers. In the session on hard materials, Dr. W. W. Barkas discussed the anisotropic elastic properties of wood, and Dr. E. Orowan dealt with steel and metals. The discussions were lively and well sustained: new views and an inter. change of ideas were rendered possible by the presence of distinguished overseas rheologists.

The research apparatus used by members were exhibited and demonstrated during the conference. Models and graphs, such as, for example, a model illustrating tractions and composition of stress and strain tensors in a unit cube, graphs showing the flow characteristics of a grease at medium rates of shear (plunger viscometer) and at high rates of shear (pendulum viscometer) were displayed. Apparatus developed for special industrial purposes were shown: these included instruments for the measurement of creep of dielectrics, the consistency of curd in cheesemaking, a rotational viscometer for fabric-printing thickeners, oil viscometer with a high range of shear rate, etc. On October 5 visits were made to the science laboratory of Mr. F. I. G. Rawlins at the National Gallery, to the G. E. C.-Osram glass works, Wembley, and the Building Research Station, Garston, where members were able to observe how rheological methods are being used in the arts and industry. Publication of the proceedings of the conference is being arranged, and it is hoped that copies also of "Essays in Rheology" (Oxford Conference) will be available in the new year. 